\title{
A Competence Approach in the Experience Feedback Process
}

\author{
Jorge Hermosillo Worley ${ }^{1}$, Holitiana Rakoto ${ }^{2}$, Bernard Grabot ${ }^{1}$ and \\ Laurent Geneste ${ }^{1}$ \\ 1) Ecole Nationale d'Ingénieurs de Tarbes, Laboratoire Gestion de Production (LGP-ENIT), \\ 47, Avenue d'Azereix - BP 1629, F-65016 Tarbes Cedex, France. \\ Email: \{hermosi, bernard, laurent\}@enit.fr \\ 2) ALSTOM Transport, Rue du Docteur Guinier-BP 4, F-65600 Séméac, France. \\ Email: holitiana.rakoto@transport.alstom.com
}

\begin{abstract}
The capitalisation of the know-how and experiences becomes a major issue of the industrial world, especially in large companies. Lesson learned techniques and experience capitalisation are possible methods for allowing the companies to increase their knowledge on their internal processes. This paper aims at presenting a study carried out with Alstom Transport on the "Experience Feedback" and "Lesson Learned" problems. We show how an Experience Feedback (EF) process, mainly aiming at transforming data into information, then information into knowledge, can benefit from an explicit modelling of concepts like role, competence and knowledge of the actors. We also show how these concepts may help to better identify the needs and potentialities of the actors, with a twofold goal: increasing the efficiency and acceptability of the EF system to be implemented on one hand, and improving the implication of the human resources in the technical processes on the other hand.
\end{abstract}

Key words: Experience feed-back, Role, Competence, Knowledge

\section{INTRODUCTION}

In order to face the quick variations of their environment, the dynamics of industrial companies have considerably increased, both in terms of product evolution, organisational changes and people mobility. Therefore, the capitalisation of the know-how and experiences becomes a major issue of the 
industrial world, especially in large companies which may be subject to an important turn over, either internal or external. Lesson learned techniques and experience capitalisation are possible methods for allowing the companies to increase their knowledge on their internal processes (see for instance AHA 1999; BICKFORD 2000; DELAHAYE 1996). Therefore, being able to re-inject the lesson learned into operational industrial processes becomes a strategic issue of nowadays companies.

This paper aims at presenting a study carried out with Alstom Transport on the "Experience Feedback" and "Lesson Learned" problems. This company designs, industrialises and ensures the maintenance of high technology devices such as power modules or command platforms of the traction part of trains, metros or tramways.

An essential factor for customer satisfaction is the high level of reliability of the products, which must be taken into account form the design phase on (Design For Reliability) and during the whole life cycle of the products. Until a recent period, the management of the reliability aspects (including diagnosis of problems and solutions) was completely dependent on the deep technical expertise of specialists whose intellectual assets clearly constitute a technical patrimony of the company. In that context, a project aiming at formalising a lesson learned process dealing with the expertise on defaults on large components has been launched in 2001, in order to structure and capitalize explicit knowledge, but also to optimise the involvement of the experts, which constitute a scarce resource in the diagnosis and solution search processes.

We show in this paper how an Experience Feedback (EF) process, mainly aiming at transforming data into information, then information into knowledge, can benefit from an explicit modelling of concepts like role, competence and knowledge of the actors. We also show how these concepts may help to better identify the needs and potentialities of the actors, with a twofold goal: increasing the efficiency and acceptability of the EF system to be implemented on one hand, and improving the implication of the human resources in the technical processes on the other hand.

The structure of the article is as follows: the experience feedback experiment launched in Alstom is described with more details in the second section. A modelling framework aiming at allowing a better description of the way the human resources are involved in the technical processes is suggested in section 3, whereas the application of this framework to the feedback process is described in section 4 . Conclusions and perspectives of this work are given in the last section. 


\section{EXPERIENCE FEEDBACK IN ALSTOM}

The input of the EF process in Alstom is the occurrence of an unexpected situation (an event) during the life cycle of a device sold to a customer. Since the event expresses an unexpected failure, a solving process is set up as soon as it is detected. This process corresponds to a sequence of activities defined according to a workflow that will lead, in the best situation, to the resolution of the problem that resulted in the event (see the upper arrow of Figure 1).

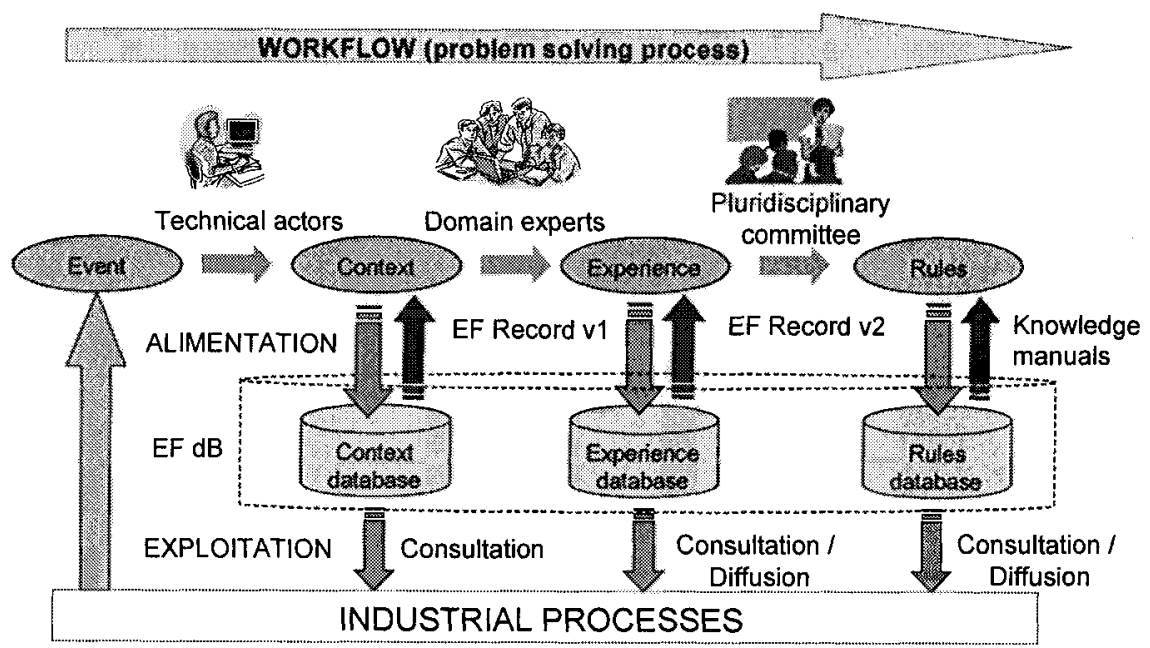

Figure 1. Global process to capture experience feedback from an event

Several activities are conducted by different groups of actors during this expertise, and will be developed later on, namely:

- "Define", where the problem is carefully stated. This activity is performed by a group of technical actors who first enhance the event description with information about the context in which it occurred (situation, working environment, first symptoms, etc.),

- "Plan", where the schedule of the expertise tasks is defined.

- "Analyse", where the identification of the problem is made and solutions are suggested. A group of experts is built for that purpose, led by the product manager, and consisting mainly of experts from the different technical areas involved in the component (electronics, electrical engineering, mechanical engineering, etc.), plus an expert on reliability.

- "Verify", where tests are performed on the products in order to check that the solutions are relevant, i.e. that the failure can not occur anymore. 
- And when possible "Generate rules", aiming at making a generalisation on several past analyses through rules which may concern the diagnosis phase, the manufacturing of the component, or even its design.

In that context, and beyond the adoption of a good solution for the problem which occurred, the aim of the experience feedback process is to capitalise the results of the expertise and to learn from it.

All along the process, the experts are chosen according to the nature of the problem to solve, determined by the type of occurring event. In that purpose, a grid is available describing the various skills of each expert. Each activity of the solving problem process feeds the EF database with $\mathrm{EF}$ records that contain the expert analysis produced during the activity (see the lower part of Figure 1). As stated above, the technical actors describe first the context of the event, which helps the experts to understand what may have happened. This context will also help later on to retrieve comparable problems in the database. The tests which are performed in order to check the first assumptions ("Verify" phase) are then stored. This structure enables to define a product/expertise net where the nodes are the EF records (see Figure 2).

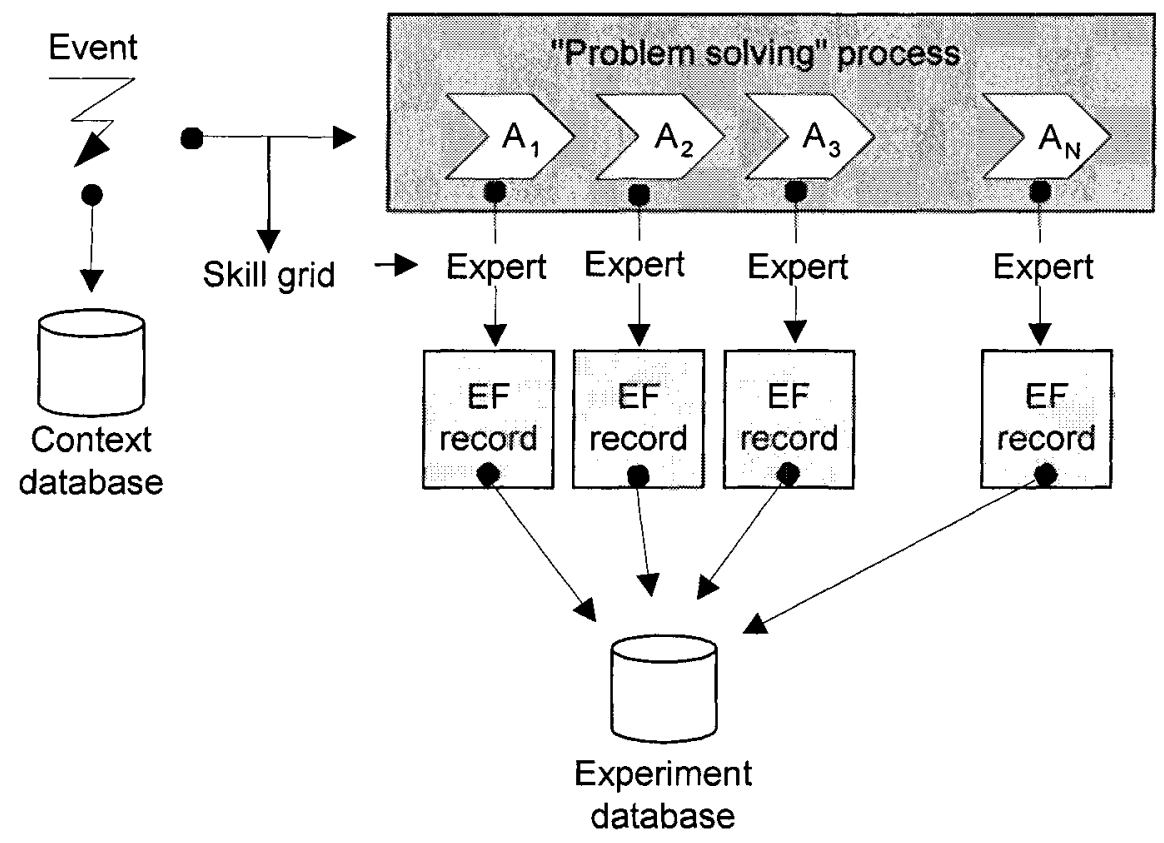

Figure 2. Experiments capitalisation 
When the solving process is achieved, it may be judicious to build rules that will be systematically applied in future developments of similar product. These rules generalise and reinforce a set of previous experiences; the elaboration of such rules involves one or several experts who will propose solutions aiming at avoiding future problems according to a set of previous experiments. Decisions are translated into rules which, once incorporated into operational industrial processes, should prevent the failure to occur on the same or on a similar product.

In all companies, high level experts are a scarce resource. Therefore, different categories describing levels of expertise have been identified at Alstom in order to prepare a better assignment of these resources to tasks. These categories have been defined according to the years of experience, recognised skills, or types of problems already solved. They are: engineer, specialist, junior expert, senior expert and master expert. Of course, experts of higher levels are more seldom and costly. It is consequently very important to optimise their allocation to the listed activities, but also to prepare the access of young experts to higher levels of expertise. For that purpose, a study has been launched in order to apply a framework developed in the research laboratory of Ecole Nationale d'Ingénieurs de Tarbes (ENIT) aiming at better identifying the characteristics of the people (operators or decision makers) involved in business processes.

\section{A MODELLING FRAMEWORK FOR HUMAN RESOURCE-BASED BUSINESS PROCESSES}

Many different sources of improvements are currently implemented in nowadays companies but although the involvement of the human resources is always considered as the key of success, it is interesting to notice that the actors are seldom explicitly described in the "as-is" or "to-be" processes. Following this observation, a modelling framework has been suggested in by HERMOSILLO et al. (2002) aiming at better integrating the human resource aspect into business processes. This framework is described here after a short panorama on the domain, and its relevance to the experience feedback process is emphasized.

\subsection{Competences and Roles in an Industrial Context}

The models allowing to represent the characteristics of the human workers have considerably evolved since the emergence of the two main ones:

- the trade model, coming from the guilds in the Middle Ages, 
- the job, employment or position model of the XVIIIth century, greatly promoted by the Taylorism at the beginning of the industrialization process.

In that context, the qualification model, still in use in most of the companies, gives a "Fordian" view on industrial manufacturing, mainly in order to help the definition of minimum salaries (PARADEISE, LICHTENBERGER et al. 2001). In response to the necessity to promote continuous improvement and flexibility, a new model has emerged in the 80's: the competence model. Instead of assessing a worker by comparison between pre-defined activities related to a workstation and the ability of a worker to perform these activities, it mainly consists in directly qualifying the person on the base of the competences which he possesses and can set to work (ZARIFIAN 2002). The main goals of the companies which promote a competence approach are identified by WUSTERMANN (2001) as the improvement of the individual efficiency, the decrease of turn-over or the improvement of the technical competences. Some companies give as the main reason of their choice the necessity to develop new competences required by the enterprise (STREBLER, BEVAN 1996) while it can also be considered that the concept of competence may provide a common language and facilitate cultural exchanges (STREBLER et al. 1997). The strategic interest of competences has been emphasized in the 90's by the work of PRAHALAD and HAMEL (1992) on the core competencies, suggesting a new way to consider the competitiveness of a company.

In most of the recent approaches, a distinction is made between the competences of a person (called here gained competences) and the competences required by an activity (required competences) (FRANCHINI et al. 1999; HARZALLAH, VERNADATH 1999). In parallel, and under different labels, a difference is made between technical competences and behavioural competences (PILBEAM, CORBRIDGE 2002), similar to the hard and soft competencies introduced by McCLELLAND (1973).

The competences can be analyzed at the level of an individual, gathering all the techniques allowing to facilitate the emergence, maintenance and development of personal competences (AMHERDT et al. 2000), but also at a collective level (LE BOTERF 1998), or even at an organizational level (SANCHEZ et al. 1996). A good summary on the different views with which the competences can be considered can be found in the competence cube suggested in the Manufacturing System Integration (MSI) research institute (WESTON et al. 2003).

Being able to explicit how the competences of the human resources may be deployed in an industrial process requires an intermediary which can be found in the concept of role of an actor. Organizations can be considered as 
systems of interacting roles (KATZ, KAHN 1966), where a role is defined as a set of activities, or as an expected behaviour. A role can be linked to a workstation, or to an organizational position (SARBIN, ALLEN 1968). The interpretation of the notion of role in the enterprise leads to define the organization as a network of roles defined independently from the persons who operate (SINGH 1992).

The modelling framework suggested in (HERMOSILLO et al. 2003) and summarized in next section aims at correlating the concepts of role, competence and knowledge in a way which can be implemented within the enterprise, especially through the notion of business process.

\subsection{Modelling Framework}

The modelling framework that we suggest is centred on the following concepts:

- Competence, which results from a combined implementation of knowledge, know-how, abilities, attitude and behaviour. More precisely, it encapsulates the ability of an individual to perform an activity in a jobrelevant area as well as what is required from an individual to realise effective performance (HERMOSILLO et al. 2003). The control of interactions in a process under all their forms - negotiation, production, regulation, execution, etc. - and whatever the activity to be assigned, requires individual and collective competences. We can identify six general competences categories: technical competences, organisational competences, analyse and decisional competences, competences of interpretation and formalisation, adaptation competences and relational or motivation competences, which can be directly related during industrial applications to the role classification described below (ibid.).

- Role, which encompass a group of functions to achieve a purpose, based on the application of role competences. Using the right person at the right moment for the right activities defining a business process significantly increases the probability that efficient, timely and high quality product and service will be realised. Based on MINTZBERG's work (1979), we identify four generic classes of roles which could be found in any kind of organisation: interpersonal roles (symbol, connection, leader); informational roles related to information flow (monitor, diffuser, spokesman); decisional roles referring to the decision-making (contractor, regulator, resources distributor, negotiator) and the operational roles related to the implementation of knowledge (expert, operator, technical bond) (HERMOSILLO et al. 2003). 
- Knowledge, which is a fluid mix of framed experience, values, contextual information, and expert insight that provides a framework for evaluating and incorporating new experiences and information. In organisations, it often becomes embedded not only in documents or repositories but also in organisational routines, processes, practices and norms (DAVENPORT, PRUSAK 1998). Knowledge can be created by persons having a given competence (e.g. the experts of the experience feedback of Alstom), but experts can also require external knowledge in order to be able to apply their competences. It is for instance the reason why multidisciplinary teams are built in the Alstom application. Therefore, identifying the required and available knowledge is also a key point for allowing to efficiently use competences in an industrial process.

These concepts are related with the process modelling principles as shown in the general model of Figure 3.

In this model we propose to distinguish between competences required by an activity and/or gained by the actor. Each of these categories has various types of basic competences which are described in the next section. The actor uses several "informational resources" which allow him to perform his role. These resources are divided into three categories, namely data, information and knowledge. Information is a structured set of data, on which has been added a meaning or an interpretation. Associating information to a context in order to define application rules allows to build knowledge. It can be verified that these definitions are fully consistent with the Experience Feedback process implemented in Alstom.

Finally, a role is based on the application of competences, which are always related to a specific activity including one or more tasks which belong to a given process, with a mission to achieve.

This general model has been instantiated on a software database tool, named COCOROL (connaissances, compétences, roles, in French), initially allowing the user to describe a process as a network of activities (execution or decision activities), where these processes can be described as either "asis" (description of existing processes) or "to-be" processes (description of optimised processes). Secondly, it is possible for the user to describe decision activities in some detail according to the defined concepts (actors, roles, competences and knowledge). The matching of human resources to "as-is" and "to-be" processes can then be done. This allows the user and process experts to know about:

- required and available roles that can be assigned in the process,

- the kind of competences that are required and available (in the company) with reference to each activity, and when these resources are used in a given process, 
- which are the data, information and knowledge sources and location, etc.

In order to be able to implement this conceptual modelling framework in industrial applications, we show in the next section how these concepts have been applied on the Alstom problematic.

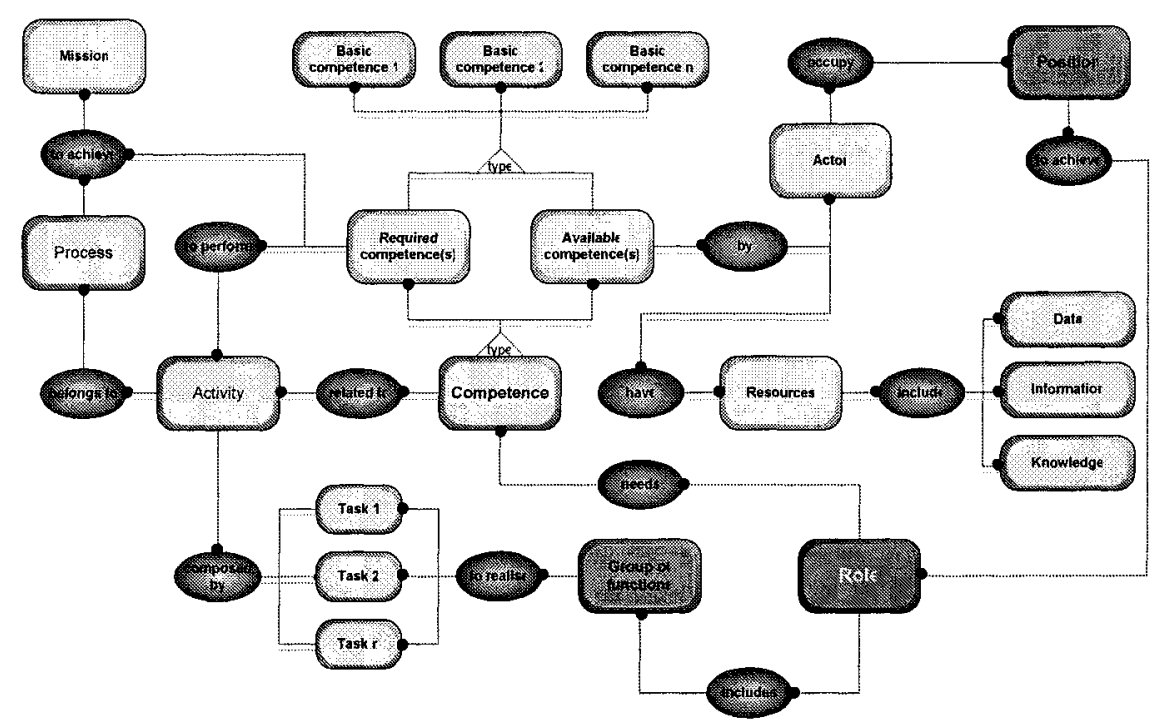

Figure 3. General model of the suggested framework

\section{APPLICATION TO THE EXPERIENCE FEEDBACK PROBLEM}

This framework has been tested on two representative activities of the EF process (see Figure 4): "Analyse" and "Generate rules" by a working group including researchers, project managers, experts and people from the Quality and Human Resources Departments.

For both activities, the same roles have been identified: Leader (project manager), Monitor (the expert in reliability, who merges external sources of information for the group) and Expert. These roles have then been more precisely described using the functional jobs of human actors concerning the analysed activities, for instance as summarised for the EF "Analyse" activity in Table 1.

The required competences for each role in each activity have then been listed. For that purpose, a list of typical competences has been built by 
merging a framework suggested by the researchers, based on comparable studies, and a framework defined by the Human Resource Department of Alstom, based on more operational issues. This framework lists:

- behavioural competences: organisational competences (compliance with rules, autonomy, responsibility, etc., interpretation and formalisation competences (ability to simplify problems, to structure information, etc.), adaptation competences (open mindedness, adaptability, stress tolerance, etc.)

- technical competences, regarding the various technical areas to be considered.

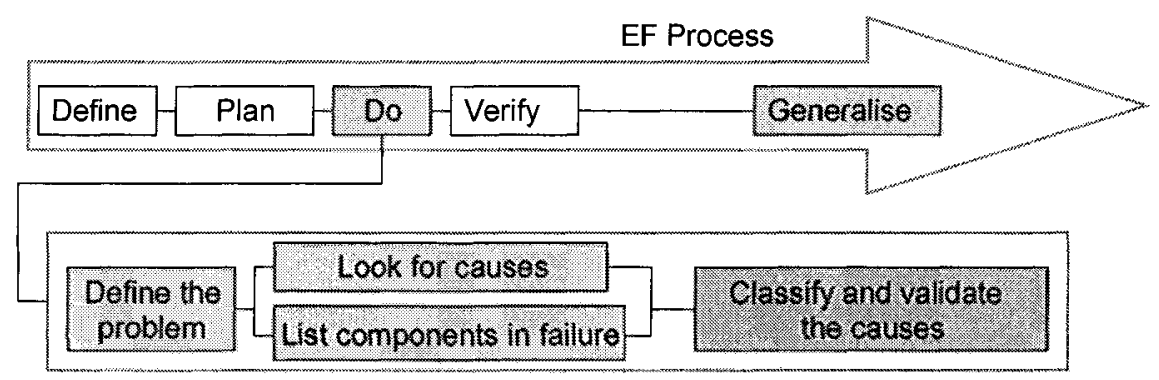

ANALYSE

Figure 4. EF process activities

All competences (19 behavioural and 20 technical competences) have been assessed according to a five-level scale which degrees have all been precisely defined.

The result of this first step is a required competence profile for each role in each considered activity, represented on radar graphics. At a second step, the actors fill up the same form together with their supervisor in order to define their available competence profiles.

These first steps of course allow to make explicit some aspects of the considered activities which are important for the expert allocation, e.g.:

- The "Generate rules" activity requires the highest level experts from a technical point of view, but also people who are able to extrapolate the possible consequences of rules on many different aspects of a product life-cycle. As a consequence, they also need to have a very wide view on the company and its strategy regarding its products.

- On the other hand, and even if their technical competencies are important, "Analyse", like many collaborative activities, requires the actors to be open and tolerant, able to clearly explain their point of view and 
understand the points of the others, which apparently are not always the dominant qualities of senior experts.

Table 1. Functional role description in the "Analyse" activity

\begin{tabular}{|l|c|l|}
\hline \multicolumn{1}{|c|}{ FUNCTION } & \multicolumn{1}{|c|}{ ROLE } & \multicolumn{1}{c|}{ ROLE DEFINITION } \\
\hline $\begin{array}{l}\text { Product / Project } \\
\text { Manager }\end{array}$ & Coordinator & $\begin{array}{l}\text { Management } / \\
\text { Communication with client }\end{array}$ \\
\hline Reliability engineer & Monitor & $\begin{array}{l}\text { Qualitative and quantitative } \\
\text { data analysis + statistical } \\
\text { data processing }\end{array}$ \\
\hline Power engineer & Expert & Power technical analysis \\
\hline $\begin{array}{l}\text { Component } \\
\text { validation engineer }\end{array}$ & Expert & $\begin{array}{l}\text { Technical component } \\
\text { analysis }\end{array}$ \\
\hline
\end{tabular}

The results of this study mainly consist in:

- A better understanding of the role of each actor in the experience feedback process.

- The identification of some divergences between required and gained competences for some individuals, mainly concerning the use of internal tools or standards of the company. This identification has allowed to define a plan for improving the knowledge of the actors on these points.

- A better identification of the technical and behavioural differences between the defined levels of expertise.

- Better positioning of the existing experts regarding the levels of expertise (who is close to the next level, what points have to be improved for allowing one to pass through the threshold, etc.)

As a consequence of the two previous points, it is now possible to complete the existing plan for managing the experts in the company, but also their evolution.

Unexpected points have also be found of interest after this study. For instance, the comparison between expected and real competence profiles may show that a person has not all the required competences, even if it can be stated that he perfectly holds his role. This may show that other competences than those identified can be applied in order to perform the role. It is in this case very interesting to explicit these competences, which may lead to new degrees of freedom in the allocation of people to tasks (i.e.: "I need a person who has competence A with level 2 or competence B with level 3."). 
Finally, the managers of the company, involved in the evaluation of their subordinates, have found the competence referential much more comprehensive than the job description which was previously in use. Therefore, it has been suggested to describe all the jobs of the site using this framework.

Another lesson learned through this study was that, unlike what was initially feared, there has been no problem around the definition and use of the behavioural competences. On the contrary, many people have found interesting to at least see explicitly what was expected from them on that aspect. Defining explicitly required behavioural competences is not anymore a taboo in large companies, as soon as some support for improvement can be given.

Concerning the tools which have been defined, even if the "matching" between the actors (available competences) and the roles (required competences) is simplified by this first analysis, it remains a complex activity since, of course, there can not be a "perfect" matching between available and required competences for activities, especially if several projects are in progress at the same time. Different types of "matching indicators" are now tested in order to address this problem, with a view close to the "similarity functions" used in Case-Based Reasoning.

\section{CONCLUSION}

Within the Alstom company, a framework has been suggested in order

i) to better identify the needs of the actors involved in various activities of an Experience Feedback process

ii) to better know which are the characteristics of the available resources.

Even if this experiment has given promising results, an important amount of work is still required in order to efficiently support the allocation of experts to tasks, but also the management of their career which is of prime interest for Alstom in order to retain them within the company. Nevertheless, in a very sensible area (identification of human competences) it is encouraging to see that a project which is clearly explained and supported at a high level in a company can lead to operational results in a rather limited period of time.

\section{REFERENCES}

AMHERDT, C. H.; DUPUICH-RABASSE, F.; EMERY, Y.; GIAUQUE, D.:

Compétences collectives dans les organisations.

Laval: Presses universitaires de Laval, 2000. 
AHA, D. W.; WEBER, R.:

Lessons learned links.

Wyoming (MD): AHA, D. W.; WEBER, R., 1999.

http://www.aic.nrl.navy.mil/ aha/lessons, 01.08.2003.

BICKFORD, C. J.:

Sharing lessons learned in the Department of Energy. Intelligent Lessons Learned Systems Workshop.

Austin, TX, 2000.

DAVENPORT, T.H.; PRUSAK, L.:

Working knowledge.

Boston, MA: Harvard Business School Press, Boston, 1998.

DELAHAYE, P.:

REX-FIAB: Un système de retour d'expérience sur la fiabilité d'équipements. 10ème

Colloque National de Fiabilité et Maintenabilité.

Saint Malo, 1996, pp. 1015-1021.

FRANCHINI, L.; CAILLAUD, E.; NGUYEN, Ph.; LACOSTE, G.:

Planning and scheduling competences: towards a human resource management in manufacturing systems.

In: International Journal of Agile Manufacturing,

Bradford, 2(1999)2, pp. 247-260.

HARZALLAH, M.; VERNADAT, F.:

Human resource competency management in enterprise engineering.

In: 14th IFAC World Congress of Information Control in Manufacturing.

Beijing: International Federation of Automatic Control (IFAC), 1999, pp. 181-186.

HERMOSILLO WORLEY, J.; GRABOT, B.; GENESTE, L.; AGUIRRE, O.:

Role, skill and Knowledge: introducing human resources in BPR.

In: Production System Design, Supply Chain Management and Logistics: 9th International Multi-Conference on Advanced Computer Systems - ACS'2002.

Eds.: DOLGUI, A.; SOLDEL, J.; ZAIKIN, O.

Miedzyzdroje: Technical University of Szczecin, 2002.

KATZ, R.; KAHN, R. L.:

The Social Psychology of Organizations.

New York, NY: Wiley \& Sons, 1966.

LE BOTERF, G.:

L'ingénierie des competences.

Paris, Les Editions d'Organisation, 1997.

McCLELLAND, D.:

Testing for Competence Rather than Intelligence.

In: American Psychologist,

Washington, DC, 28(1973)1, pp. 1-14.

MINTZBERG, $\mathrm{H}$.:

The structuring of organisations,

Upper Saddle River, NJ: Prentice Hall, 1979.

PARADEISE, C.; LICHTENBERGER, Y.:

Compétence, competences.

In: Sociologie du travail, Editions Scientifiques et Médicales

Paris, 43(2001)1, pp. 33-48.

PILBEAM, S.; CORBRIDGE, M.:

People Resourcing - HRM in Practice.

New York, NY: Prentice-Hall, 2nd ed., 2002. 
PRAHALAD, C. K.; HAMEL, G.:

The core competence of the corporation.

In: IEEE Engineering Management Review, New York, NY, 20(1992)3, pp. 5-14.

SANCHEZ, R.; HEENE, A.; THOMAS, H.:

Dynamics of Competence-based Competition.

Amsterdam: Elsevier Science, 1996.

SARBIN, T. R.; ALLEN, V. L.:

Role theory.

In: Academy of social psychology.

Eds.: LINDZEY, G.; ARONSO, E.

New York: Random House, 2nd ed., Volume 1, 1968, pp. 488-567.

SCHEER:

ARIS Toolset documentation.

Saarbrücken: Scheer AG, 1999.

SINGH, B.:

Interconnected Roles (IR): A coordination model.

Austin, TX: Microelectronics and Computer Technology Corporation, 1992.

(MCC Technical Report CT-084-92)

STREBLER, M.; BEVAN, S.:

Competence Based Management Training.

Brighton: Institute of Employment Studies, 1996.

(Report 302)

STREBLER, M.; THOMPSON, M.; HERON, P.:

Skills, Competencies and Gender: Issues for Pay and Training.

Brighton: Institute of Employment Studies, 1997.

(Report 333)

WESTON, Richard H.; BYER, Nikita; AJAEFOBI, Joseph O.:

EM in support of team system engineering.

In: Proceedings of 10th ISPE International Conference on Concurrent Engineering: The Vision for the Future Generation in Research and Applications.

Eds.: JARDIM-GONCALVES, R., BALKEMA, J., CHA J., STEIGER-GARAO A.

Lisse: Swets \& Zeitlinger, 2003, pp. 865-872.

WUSTERMANN, L.:

Recruitment, retention and return in the NHS.

In: Health Service Report, 32(2001)autumn, pp. 2-14.

ZARIFIAN, P.:

La politique de la compétence et l'appel aux connaissances dans la stratégie d'entreprise.

In: Vers l'articulation entre compétences et connaissances.

Nantes: Groupe de Travail Gestion des Compétences et des Connaissances en Génie

Industriel (GCCGI), 2002, pp. 20-24. 